\title{
SPATIALLY RESOLVED TEMPERATURE AND GAS SPECIES CHANGES IN A LEAN-BURN ENGINE EMISSIONS CONTROL CATALYST
}

\author{
April Russell , William S. Epling*, Osama Shakir, Cary Henry, Neal W. Currier and \\ Aleksey Yezerets \\ University of Waterloo and Cummins Inc
}

\begin{abstract}
Summary
Infra-red thermography and spatially-resolved capillary inlet mass spectrometry (SpaciMS) have been used to characterize hydrocarbon oxidation reactions occurring along a $\mathrm{Pt} / \mathrm{Al}_{2} \mathrm{O}_{3}$ monolith-supported catalyst, before and after thermal degradation. The combined techniques clearly show reaction location, and therefore catalyst use, and how these change with thermal aging. Two modes of thermal degradation were applied, one where the entire catalyst was exposed to one temperature and one where the upstream portion of the catalyst was exposed to high temperature. Results from both will be presented and compared.
\end{abstract}

Keywords

Environmental Reaction Engineering, Reaction Path Analysis

\section{Introduction}

Vehicle exhaust emissions catalysts are typically supported on honeycomb monolith structures. Such catalysts are integral devices, and gradients in reactant and product species concentrations exist and evolve along the surface and in the gas-phase during operation. As a result of changing reactant concentrations, gradients in reaction extents exist leading to gradients in temperature, and due to these different concentrations and temperatures, the kinetics of the different reactions occurring on the surface are not uniform along the direction of flow. Furthermore, in operation, significant temperature differences can exist between upstream versus downstream regions along the monolith, resulting in non-uniform thermal degradation along the catalyst.

There has been significant modeling efforts directed at accurately predicting the reaction rates and extents within a monolith-supported catalyst, as well as the effect of a number of variables on the overall performance. Experiments designed to measure and provide relevant complimentary data to validate the simulation efforts however are lacking. The conventional method for resolving temperature measurements is positioning an array of thermocouples along the axis of the reactor [1]. There has also been work using IR thermography to observe spatial variations in temperature over catalysts [2] and is a less intrusive method. In terms of gas-phase concentration measurements, Oak Ridge National Laboratory has been developing spatially resolved capillary-inlet mass spectrometry (SpaciMS), which is a method to measure transient gas-phase concentration profiles $[3,4]$.

In this work, IR thermography and SpaciMS measurements were combined to characterize temperature and gas species concentrations gradients during propylene and $\mathrm{NO}$ oxidation over a $\mathrm{Pt} / \mathrm{Al}_{2} \mathrm{O}_{3}$ monolith-supported catalyst before and after thermal aging.

\section{Materials and Methods}

SpaciMS was used to measure the gas-phase species within a 2" long, model, monolith-supported $\mathrm{Pt} / \mathrm{Al}_{2} \mathrm{O}_{3}$ catalyst and IR thermography was used to measure the surface temperatures. One set of measurements was made during temperature ramps with the capillary positions fixed and the other with a constant inlet temperature and the reactants then introduced. $0.45 \% \mathrm{C}_{3} \mathrm{H}_{6}, 6.5 \% \mathrm{O}_{2}$ and 0 or $3 \% \mathrm{H}_{2} \mathrm{O}$ were mixed with a balance of $\mathrm{N}_{2}$. Experiments were performed with an unaged sample, one aged externally from the furnace at $675^{\circ} \mathrm{C}$ in air and one aged in the reactor by pulsing $\mathrm{C}_{3} \mathrm{H}_{6}$ and $\mathrm{O}_{2}$ into the reactor while the upstream temperature was high enough to ensure lightoff and reaction occurred only on the upstream portion of the sample This resulted in a heterogeneous thermal degradation pattern. 


\section{Results and Discussion}

IR thermography and $\mathrm{C}_{3} \mathrm{H}_{6}$ gas concentration data obtained from the unaged sample during a temperature programmed oxidation (TPO) experiment are shown in Figure 1 as an example of the results obtained. These data clearly show where reaction was occurring in the monolith, and changes in the reaction profile as a function of time. Under the conditions tested, back-to-front oxidation lightoff was observed, due to a combination of convection, conduction and heat of reaction effects.
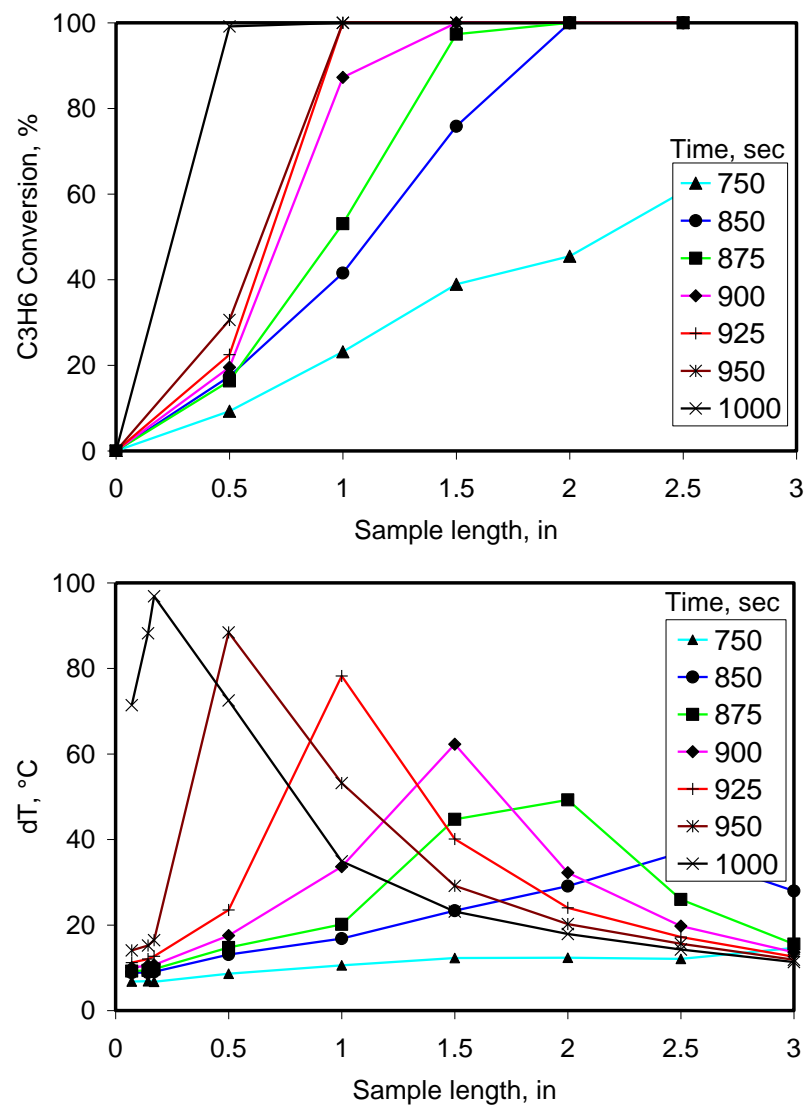

Figure 1: $\mathrm{C}_{3} \mathrm{H}_{6}$ gas concentration (top) and temperature rise (bottom) measurements as a function of time and position for the unaged sample.

At 0.5 in. from the inlet, $<10 \%$ conversion was observed at 750 seconds, and increased to $15 \%$ by 875 seconds. Further downstream, at 1.0 in., this increase was more significant over the same time period, from 20 to $50 \%$, while at $2.0 \mathrm{in}$. from the inlet, the $\mathrm{C}_{3} \mathrm{H}_{6}$ conversion went from 40 to $100 \%$ in that same 125 seconds. These data at $2.0 \mathrm{in}$. indicate that the reaction front had already passed that position at 875 seconds, however at 750 seconds, the reaction zone extended all the way from the inlet to what is sometimes described as the reaction front, and was not just within a small portion of the catalyst. This reactive portion decreased in size as the front propagated upstream, as demonstrated in evaluating the data obtained at 950 seconds; $100 \%$ conversion was observed at both 1.0 and 2.0 in., but only $30 \%$ was attained at the 0.5 in. location. Thus, at 950 seconds the reaction was complete somewhere between 0.5 and $1.0 \mathrm{in}$. from the inlet.
In terms of temperature data, at 875 seconds, the temperature rise had increased by $\sim 10^{\circ} \mathrm{C}$ at 0.5 in., $11^{\circ} \mathrm{C}$ at 1.0 in. and $40^{\circ} \mathrm{C}$ at 2.0 in.. These thermography data indicate a sharp increase in conversion and reaction between 1 and 1.5 in., consistent with the conversion data discussed above. Similarly, after 950 seconds, there was a $90^{\circ} \mathrm{C}$ temperature rise by 0.5 in. into the sample, with significantly less at 0.18 and 1.0 in. locations, indicating the reaction zone resided between those two points. The conversion data suggest that the light-off front was between 0.5 and 1.0 in., again consistent with the thermography data. Similar data clearly showing reaction profiles in the catalyst were obtained from the thermally aged sample.

As another highlight to be discussed, changes in the temperature and concentration profiles before and after thermal degradation were compared (Figure 2) and show that after thermal degradation the ignition front moved toward the inlet significantly more slowly relative to the non-thermally degraded sample.

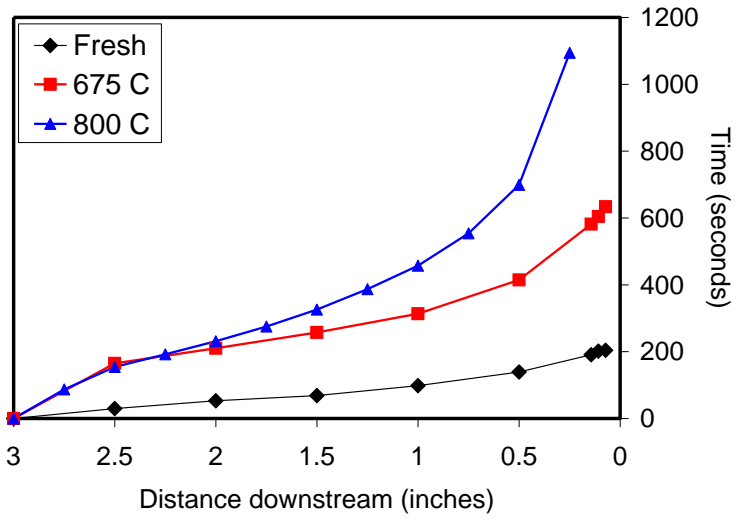

Figure 2: Time for the reaction front to traverse the back of the monolith to each of the nine positions for which the spatiotemporal temperature profiles were obtained.

\section{References}

(1) Sun, M.; Croiset, E.; Hudgins, R.; Silveston, P. SteadyState Multiplicity and Superadiabatic Extinction Waves in the Oxidation of $\mathrm{CO} / \mathrm{H}_{2}$ Mixtures over a $\mathrm{Pt} / \mathrm{Al}_{2} \mathrm{O}_{3}$-Coated Monolith. Industrial and Engineering Chemistry Research 2003, 42, 37.

(2) Pawlicki, P.; Schmitz, R. Spatial Effects in Supported Catalysts. Chemical Engineering Progress 1987, 83, 40.

(3) Choi, J.S.; Partridge, W.P.; Daw, C.S. Spatially resolved in situ measurements of transient species breakthrough during cyclic, low-temperature regeneration of a monolithic $\mathrm{Pt} / \mathrm{K} / \mathrm{Al}_{2} \mathrm{O}_{3} \quad \mathrm{NOx}$ storage-reduction catalyst. Applied Catalysis A: General 2005, 293, 24.

(4) Partridge, W.P.; Storey, J.M.E.; Lewis, S.A.; Smithwick, R.W.; DeVault, G.L.; Cunningham, M.J.; Currier, N.W.; Yonushonis, T.M. Time-resolved measurements of emission transients by mass spectrometry. SAE Technical Paper Series 2000-01-2952. 